\title{
Erratum to: Tumor suppressive pathways in the control of neurogenesis
}

\author{
Stefano Bartesaghi $\cdot$ Paolo Salomoni
}

Published online: 21 May 2013

(C) Springer Basel 2013

Erratum to: Cell Mol Life Sci (2013) 70:581-597

DOI 10.1007/s00018-012-1063-9

In the original publication of the article one of the references included in the review "Tumour suppressive pathways in the control of neurogenesis" was not correctly discussed.

The sentence on page 586, "Retinoblastoma phosphorylation by CDKs relieves repression of E2F transcriptional activity, thus promoting cell cycle progression $[139,140]$." should read:

"Rb phosphorylation by Cyclin/CDKs has been proposed to relieve repression of E2F transcriptional activity and promote cell cycle progression, but this concept is currently being revisited mainly through the work of Cooper and collaborators $[139,140]$, thus suggesting that $\mathrm{Rb}$ regulation is more complex than previously thought."

The online version of the original article can be found under doi:10.1007/s00018-012-1063-9.

S. Bartesaghi $\cdot$ P. Salomoni $(\bowtie)$

Samantha Dickson Brain Cancer Unit, UCL Cancer Institute,

72 Huntley Street, London WC1E 6DD, UK

e-mail: p.salomoni@ucl.ac.uk 